\title{
BMJ Open Identifying relationships between sleep posture and non-specific spinal symptoms in adults: A scoping review
}

\author{
Doug Cary, ${ }^{1,2}$ Kathy Briffa, ${ }^{1}$ Leanda McKenna ${ }^{1}$
}

To cite: Cary D, Briffa K, McKenna L. Identifying relationships between sleep posture and non-specific spinal symptoms in adults: A scoping review. BMJ Open 2019;9:e027633. doi:10.1136/ bmjopen-2018-027633

- Prepublication history and additional material for this paper are available online. To view please visit the journal (http:// dx.doi.org/10.1136/bmjopen2018-027633).

Received 1 November 2018 Revised 1 April 2019 Accepted 30 May 2019

Check for updates

(C) Author(s) (or their employer(s)) 2019. Re-use permitted under CC BY-NC. No commercial re-use. See rights and permissions. Published by BMJ.

${ }^{1}$ School of Physiotherapy and Exercise Science, Faculty of Health Sciences, Curtin University, Perth, Western Australia, Australia

${ }^{2}$ AAP Education, Esperance, Western Australia, Australia

Correspondence to

Mr Doug Cary;

doug@aapeducation.com.au

\section{ABSTRACT}

Objectives The objectives of this scoping review were to identify (1) study designs and participant populations, (2) types of specific methodology and (3) common results, conclusions and recommendations from the body of evidence regarding our research question; is there a relationship between sleep posture and spinal symptoms. Design Scoping review.

Data sources PEDro, Embase, Cumulative Index to Nursing and Allied Health Literature, Cochrane Library, Medline, ProQuest, PsycINF0, SportDISCUS and grey literature from inception to 10 April 2018.

Data selection Using a modified Arksey and 0'Malley framework, all English language studies in humans that met eligibility criteria using key search terms associated with sleep posture and spinal symptoms were included. Data extraction Data were independently extracted by two reviewers and mapped to describe the current state of the literature. Articles meeting the search criteria were critically appraised using the Downs and Black checklist. Results From 4186 articles, four articles were identified, of which three were epidemiological and one interventional. All studies examined three or more sleep postures, all measured sleep posture using self-report and one study also used infrared cameras. Two studies examined symptoms arising from the lumbar spine, one the cervical spine and one the whole spine. Waking pain and stiffness were the most common symptoms explored and side lying was generally protective against spinal symptoms.

Conclusions This scoping review highlights the importance of evaluating sleep posture with respect to waking symptoms and has provided preliminary information regarding relationships between sleep posture and spinal symptoms. However, there were not enough high-quality studies to adequately answer our research question. It is recommended future research consider group sizes and population characteristics to achieve research goals, that a validated measure be used to assess sleep posture, that characteristics and location of spinal symptoms are clearly defined and that the side lying posture is subclassified.

\section{INTRODUCTION}

Cervical and lumbar symptoms like pain are the leading cause of musculoskeletal disability in most countries and most age groups. ${ }^{1}$ Of those who report cervical and lumbar pain,

\section{Strengths and limitations of this study}

This is the first scoping review collating and synthesising the available literature on sleeping posture and non-specific spinal symptoms.

- A critical appraisal of evidence assessment was undertaken for each included study.

- The lack of studies and small group sizes prevented firm recommendations regarding all sleep postures.

the proportion is higher in females for both cervical $(59 \%)^{2}$ and lumbar $(52 \%)$ pain. ${ }^{3}$ The prevalence of both cervical and lumbar pain has increased markedly over the past 25 years (cervical $21.1 \%$ and lumbar $17.3 \%$ ), and these rates are expected to continue rising. ${ }^{1}$ Cervical and lumbar pain contribute to large economic and societal costs and are major sources of work disability, being either the first or second ranked cause of years lived with disability between the ages of 20 and 79 years. ${ }^{145}$ Research indicates that remissions in symptoms are temporary rather than permanent ${ }^{67}$ and cervical and lumbar pain becomes chronic in $25 \%-60 \%$ of cases. ${ }^{8}$ Other types of symptoms like stiffness and bothersomeness, still important to patients, are less well investigated. $^{910}$ Identification of modifiable risk factors contributing to the onset and chronicity of cervical and lumbar pain and other symptoms is critical ${ }^{11}$ to improve the management of cervical and lumbar pain.

A potentially modifiable risk factor that aggravates spinal symptoms is sleep posture. Sleep is considered essential for human mental and physical recovery. Yet, every night some people go to bed, only to wake with spinal symptoms not present the prior evening, while others with existing spinal symptoms, wake with exacerbations of their symptoms. $^{12} 13$ For example, in young air force personnel, 33\% experienced their most intense spinal pain during the evening and on first waking. ${ }^{12}$ It has been postulated that poor sleep posture may be a factor in the 
development of both waking cervical ${ }^{14-16}$ and lumbar symptoms. ${ }^{17} 18$

Habitual sleep postures may influence the amount of load applied to spinal tissues when sleeping. Compressive load due to gravity and muscle contraction ${ }^{19} 20$ is likely to be far more during the day than during the night. In a 25-year review on the fundamentals of spinal biomechanics, it was noted that spinal movements decreased under a superimposed compression load. The author postulated this was due to increased anular stiffness and increased zygapophyseal joint (ZPJ) contact. ${ }^{21}$ Conversely, when lying down, the sources of spinal compression are minimal, creating a low compression environment, potentially allowing an increased range of spinal movement. The combination of increased range and asymmetrical loading posture may result in altered and/or additional loading of viscoelastic collagenous restraints like the ZPJ capsule and ligaments. ${ }^{22}$ Viscoelastic tissues are vulnerable to sustained or repeated low elongation loads, and undergo predictable mechanical and viscoelastic changes. Ligaments in feline spines exposed to $60 \mathrm{~min}$ of repeated low load, demonstrate a significant increase in the expression of pro-inflammatory chemicals, compared with control ligaments from the same spine, indicating acute inflammation and tissue degradation in ligaments subjected to the cyclic loading. ${ }^{23}$ Additionally, sustained non-symmetrical sleep postures can induce structural spinal changes in humans. ${ }^{24}{ }^{25}$ Sleep postures have been shown to be modifiable ${ }^{1726}$ and identification of modifiable risk factors related to spinal pain, have been highlighted as a priority in managing disabling lumbar pain. ${ }^{27}$

Some sleep postures, such as prone, are clinically believed to increase load on spinal tissues, reducing recovery and provoking waking spinal symptoms. ${ }^{18} 2829$ While some sleep research has examined, the role sleep posture may have on spinal symptoms, ${ }^{13} 1730$ there has been no synthesis of the literature in regard to sleep posture and spinal symptoms.

\section{METHODS}

\section{Search framework}

This scoping review was developed using the methodological framework proposed by previous authors, ${ }^{31}$ further refined by other independent authors and institutes ${ }^{32-34}$ and reported in line with key Preferred Reporting Items for Systematic Reviews and Meta-Analyses for scoping reviews (PRISMA) guidelines. ${ }^{35}$

\section{Research question}

Following an individual review of the literature and a group meeting, authors' consensus was reached to determine the following research question; is there a relationship between sleep posture and spinal symptoms?

\section{Aim and objectives}

The aim of this scoping review was to gain a clear understanding of the current knowledge base in relation to the identified research question. To achieve this aim, an iterative process involving electronic meetings and communication between authors was used to determine the following research objectives:

- Identify what study designs and participant populations have been studied to answer the research question.

- Identify the types of specific methodology used in the body of evidence to address the research question.

- Identify common results, conclusions and recommendations from the body of evidence regarding the research question.

\section{Eligibility criteria}

Eligibility criteria were based on the population, intervention, comparison and outcome (PICO) framework. A draft list of eligibility criteria was initially determined following the independent screening of relevant articles by two reviewers. Criteria were then developed iteratively between two reviewers and a finalised list of criteria were uploaded to Covidence, ${ }^{36}$ as a reference for data charting reviewers.

\section{Inclusion criteria}

For inclusion in this scoping review, the prior research needed to study participants 18 years or older, with either pain, stiffness or bothersomeness in the cervical, thoracic or lumbar spine. Any observational or interventional study examining the relationship between sleep posture and spinal symptoms was considered. Articles that either compared sleep posture change (eg, before and after an intervention) or had no comparator (eg, epidemiological) were included. Articles needed to use a subjective or objective measure for symptoms and sleeping posture.

\section{Exclusion criteria}

Articles were excluded if they involved animals, cadavers or included participants diagnosed with sleep apnoea, spinal stenosis, migraine, red flag pathologies (eg, neoplasm, inflammatory conditions, fractures or infections); participants with pain of known non-spinal origin (eg, kidney disease, postoperative pain, temporomandibular joint, shoulder pain); participants with neurological conditions (eg, multiple sclerosis, cerebrovascular accident); or participants who were unable to move freely in bed (eg, using continuous positive airway pressure therapy or in the last trimester of pregnancy). Articles were excluded if they did not isolate the intervention when a group of interventions were implemented (eg, spinal injection and sleeping posture) or if they compared sleep systems (eg, mattress, base and or pillow) or changes in sleep systems but did not report the change in sleep posture. Further, articles using actigraphy to measure movement or articles that only examined the quality or efficacy of sleep were excluded. Finally, editorials, opinion-based articles, review articles (systematic or narrative) and articles not written in English were excluded. 


\section{Patient and public involvement}

Patients and the public were not involved in this scoping review.

\section{Search terms and strategy}

The PICO framework was used to assist in the collation of all elements relevant to clinical research questions. Population: Terms used for the search strategy were chosen to be representative of the areas and symptoms, likely to be experienced by a population with non-specific spinal symptoms. Non-specific symptoms are those not related to fracture, infection, inflammatory disease, tumour or spinal stenosis. Intervention: Terms representative of interventions aimed at changing sleep posture in association with spinal symptoms were considered for inclusion, while other terms not associated with spinal symptoms, for example, apnoea were excluded. Comparison: Terms were considered that were indicative of any type of comparison. Outcome: Any terms to indicate the subjective measure of pain, stiffness or bothersomeness or objective measure used to evaluate sleep posture were considered.

Identified key search terms were then used in the search strategy to identify all relevant articles. An initial search was conducted in two of the four databases, recommended $^{37}$ for physiotherapy related topics; PEDro and Embase (via Ovid) from inception to December 2017. The initial search was used to determine if the search terms and strategy were appropriate, and informed the development of the final search terms and strategy.

The final search strategy was conducted using the search terms and Boolean logic as described in online supplementary file 1 and adapted for eight electronic databases (PEDro, Embase, Cumulative Index to Nursing and Allied Health Literature, Cochrane Library, Medline, ProQuest, PsycINFO, SportDISCUS) with the assistance of a health sciences information specialist. Grey literature (espace, Google Scholar (top 100 references scanned for relevance) and Web of Science) was searched for difficult to locate or unpublished material that had not already been included. The final step involved manual searching the reference sections of relevant articles and publications by key authors for additional articles, not identified in the original search.

\section{Study selection}

All search results were imported into the reference management software package, EndNote V.X ${ }^{38}$ and duplicates removed. Remaining results were imported into Covidence ${ }^{36}$ and additional duplicates removed. Using Covidence, two reviewers independently performed level 1 (title and abstract) and level 2 (full text) screening, based on the eligibility criteria. Differences of opinion in which articles progressed to the next level were first resolved with discussion between reviewers and if necessary, with input from a third reviewer.

\section{Data charting}

The data charting form was developed and revised iteratively between reviewers to ensure data relevant to the three research objectives were collected. A definitions and instructions document was developed to ensure that data were collected consistently by the independent reviewers. The data charting form was then independently pilot tested in duplicate on a random sample of four potential articles. Following identification of articles for inclusion in this review, data were independently charted in duplicate using a data charting form created in Excel and based on the three research objectives. An attempt was made to contact authors of eligible articles where authors reported that data relevant to our scoping review had been collected but was not publicly available, and to clarify points relevant to our data charting.

\section{Quality of evidence}

Non-assessment of methodological quality and the risk of bias are consistent with current guidelines on conducting a scoping review. ${ }^{32}$ However, a focus of this scoping review was on methodology; therefore, a methodological assessment of quality was included. The Downs and Black checklist $^{39}$ was chosen, as it has documented criterion validity, face and content validity, intrarater $(r=0.88)$ and inter-rater reliability $(\mathrm{r}=0.75)$ and guidelines for use. ${ }^{40}$ A modified version of the Downs and Black checklist, ${ }^{41}$ where a dichotomous score for power (question 27), was used. As a result, the maximum score for randomised trials was 28 and for non-randomised trials it was 25 . The Downs and Black checklist was independently completed for each article in duplicate. Differences in scoring were first resolved by consensus between reviewers and if required, by a third independent reviewer. Study limitations noted by authors were collected to compliment the Downs and Black checklist.

\section{RESULTS}

\section{Search results}

An overview of the article identification process is provided in the PRISMA flow diagram in figure 1. Articles excluded due to wrong outcomes were those that did not include a measure of sleep posture or only examined sleep posture and not symptoms, tested a sleeping system (eg, mattress or pillow) in relation to spinal symptoms but not posture, or studied sleep posture in relation to sleep quality. Articles excluded due to wrong study design included treatment guidelines, opinion and editorial pieces and summaries.

\section{Study design and population characteristics}

The designs of the four included studies were mixed (table 1).

\section{Methodology: Sleep posture measurement}

All studies examined participants in their domestic environment (table 2) and described as a minimum the three common sleep postures; supine, side lying and prone. One study described four sleep postures, dividing side lying into two sleep postures and named them supportive side 


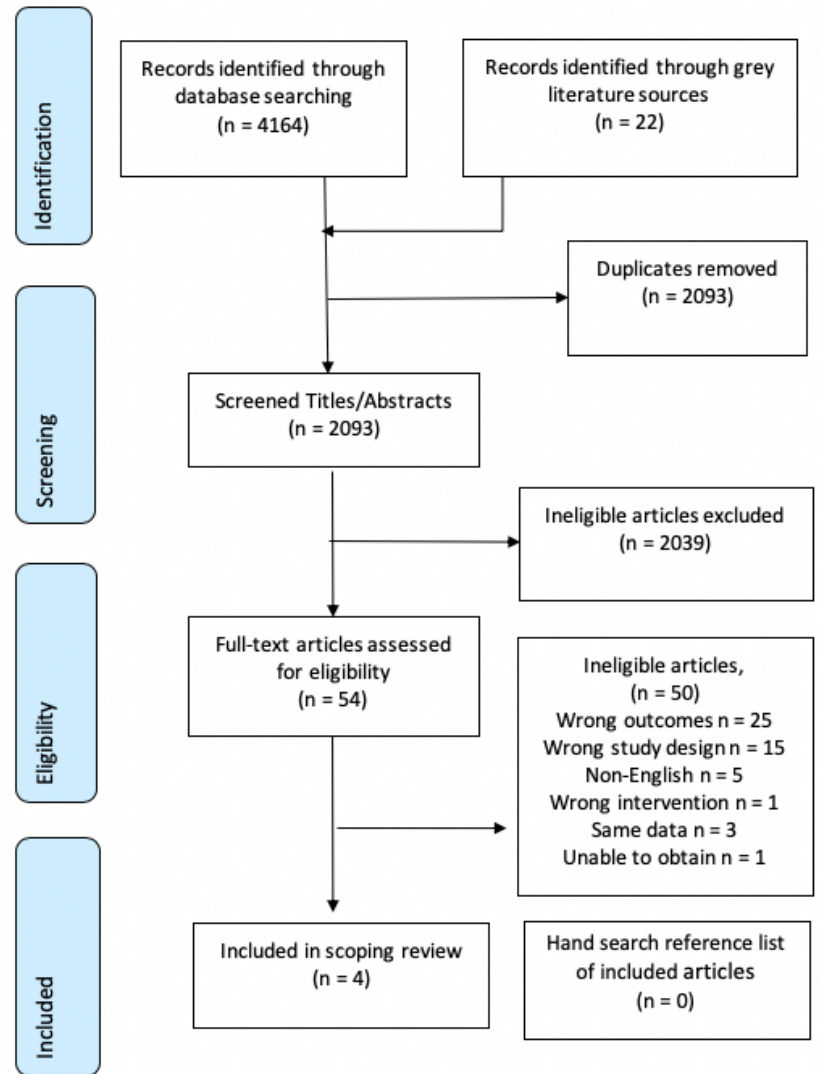

Figure 1 PRISMA flow diagram. PRISMA, Preferred Reporting Items for Systematic Reviews and Meta-Analyses.

lying and $3 / 4$ side lying. ${ }^{42}$ Another described five postures, adding 'upright' and 'varies', to the common three sleep postures. ${ }^{13}$ One study used three different postures, but combined side lying and prone for analysis, due to small number of prone sleepers, of whom none reported lumbar pain. ${ }^{43}$ All studies used self-report questionnaires to assess sleep posture. Studies focused on different time points when questioning about sleep posture. Two specifically focused on night and waking posture; 'in what sleep posture do you usually go to sleep', 'in what sleep posture do you usually wake up' and 'in what sleep posture do you spend most of the night ${ }^{13}(\mathrm{p} 7)$, and 'which posture most closely resembles the posture you are lying in when you fall asleep?' and 'which posture most closely resembles the posture you are lying in when you wake up?'. The other two studies were non-specific, 'usual sleep posture' $^{43}$ (p335) and 'informal questionnaire for... sleeping position' ${ }^{17}$ (p237). In addition to using self-report, the authors of one study used an objective method of assessment, twin camera infrared video recording, to verify sleep posture. ${ }^{42}$

\section{Methodology: measurement of symptoms}

The anatomical location, characteristics and method of measuring spinal symptoms are presented in table 2. One study included non-spinal symptoms (eg, hip and legs) classified as 'other'. ${ }^{42}$ All studies examined pain (with two studies examining additional symptoms), but differed in regard to examining intensity, frequency, period of symptoms and diurnal/nocturnal presence. In one study, participants answered a 'question on LBP history, such as present and past low back history ${ }^{43}$ (p333) and another asked participants 'the frequency and location of morning symptoms of spine pain and stiffness that occurred during the past month ${ }^{, 42}$ (p2). In the other two studies, one described the frequency and duration of morning pain and stiffness over the prior week, but not intensity ${ }^{13}$ while the other used a Visual Analogue Scale (VAS) to measure pain intensity 'at moment of response' but not frequency or duration ${ }^{17}$ (p237).

\section{Methodology: interventions and follow-ups}

Only participants in the treatment group of the intervention study ${ }^{17}$ received sleep posture education. Those with dorsal or lumbar symptoms were advised to sleep supine, those with cervical symptoms were advised to sleep in side lying and prone sleepers were advised to adopt either of the prior recommended sleep postures. Participants were also educated about the use of pillows and how to get up and lie down. The control group received no instruction and neither group received further contact until reassessment. The intervention phase lasted 4 weeks. A significant reduction in pain was reported in the treatment group but not the control group. However, sleep

Table 1 Mapping of study design and population characteristics

\begin{tabular}{|c|c|c|c|c|}
\hline Author & Study design & Population type & $\begin{array}{l}\text { Sample size } \\
\text { (Gender) }\end{array}$ & Age M (SD) \\
\hline Abanobi et al, ${ }^{43} 2015$ & $\begin{array}{l}\text { Epidemiological: } \\
\text { case controlled }\end{array}$ & Welders in Owerri, Nigeria & $100($ male $=100)$ & $35(9)$ \\
\hline Cary et al, ${ }^{42} 2016$ & $\begin{array}{l}\text { Epidemiological: } \\
\text { cross-sectional }\end{array}$ & $\begin{array}{l}\text { Population of convenience in Esperance, } \\
\text { Western Australia }\end{array}$ & $15($ male $=7)$ & $44(17)$ \\
\hline Desouzart et al, ${ }^{17} 2016$ & Controlled pilot & $\begin{array}{l}\text { Elderly participants in physical activity } \\
\text { programme at Polytechnic Institute of } \\
\text { Leiria, Portugal }\end{array}$ & $20($ male $=0)$ & $62(4)$ \\
\hline Gordon et al, ${ }^{13} 2007$ & $\begin{array}{l}\text { Epidemiological: } \\
\text { cross-sectional }\end{array}$ & $\begin{array}{l}\text { Every third household in Port Lincoln in } \\
\text { South Australia }\end{array}$ & $812($ male $=261)$ & $\begin{array}{l}\text { Female } 61(10) \\
\text { Male } 59(11)\end{array}$ \\
\hline
\end{tabular}

$\mathrm{M}=$ mean, $\mathrm{SD}=$ standard deviation 
posture was not objectively confirmed at baseline or after the intervention period.

Results, conclusions and recommendations

Results from all studies reported trends or significant associations between spinal pain and certain sleep postures (table 3). The authors from three studies reported increased symptoms, one associated with supine ${ }^{43}$ one upright ${ }^{13}$ and the other in prone or $3 / 4$ side lying $^{42}$ sleep postures. The authors from two studies reported significantly decreased symptoms, one with side lying ${ }^{13}$ and the other a combination of side lying and supine. ${ }^{17}$ In the intervention study, the authors reported a significant reduction in pain VAS for the intervention group but not the control group. ${ }^{17}$ Between-group comparisons were not reported, possibly because it was a pilot study. We used an online calculator ${ }^{44}$ to determine an effect size with $95 \%$ CIs between groups, using baseline to postintervention data in two steps. Baseline to postintervention change was used because a significant difference between groups existed at baseline. First, a pooled SD for each group was calculated for change from baseline to final measure. Then this pooled SD from each group was used to calculate the between group effect size and 95\% CI (see table 3). The resultant CI indicates that significant differences between groups were unlikely. To calculate an effect size for Cary et $\mathrm{al}^{42}$ the independent samples Jonckheere-Terpstra test ${ }^{45}$ was used to calculate a z-score, which was then converted into an effect size $\left(r_{j}\right) .{ }^{46}$

Conclusions from authors of all four studies were that sleep posture could increase or decrease spinal pain, and that addressing sleep posture could reduce the development of spinal pain. Using self-report, side lying was reported as protective of spinal symptoms ${ }^{13} 17$ and participants that slept in supported side lying were found to have less symptoms than those sleeping in $3 / 4$ side lying or prone. ${ }^{42}$ In regard to supine, one study found supine increased the likelihood of lumbar pain by 1.9 times, ${ }^{43}$ another study recommended supine in combination with side lying sleep postures to reduce lumbar pain $^{17}$ and a third reported supine was not significantly protective of cervical waking symptoms. ${ }^{13}$

Two studies recommended clinicians consider sleep posture to reduce cervical ${ }^{13}$ and lumbar symptoms. ${ }^{17}$

\section{Quality of evidence and author reported limitations}

The quality of evidence is summarised in table 4 . The Downs and Black checklist contains 27 questions distributed over five domains; reporting (ie, aims, sampling and methods); external validity (ie, generalisability); internal validity (ie, study design, selection bias, performance and reporting bias); confounding and power. ${ }^{39}$ Using the Downs and Black checklist as the appraisal tool, evidence levels have previously been categorised as strong $(>75 \%)$, moderate $(50 \%-74 \%)$, limited (25\%$49 \%)$ and poor quality $(<24 \%) \cdot{ }^{47}$ Questions $4,8,9,13$, $14,15,19,23,24$ and 26 (see table 4 for details) were not applicable to study designs that did not include an 
Table 3 Mapping of results, conclusions and recommendations

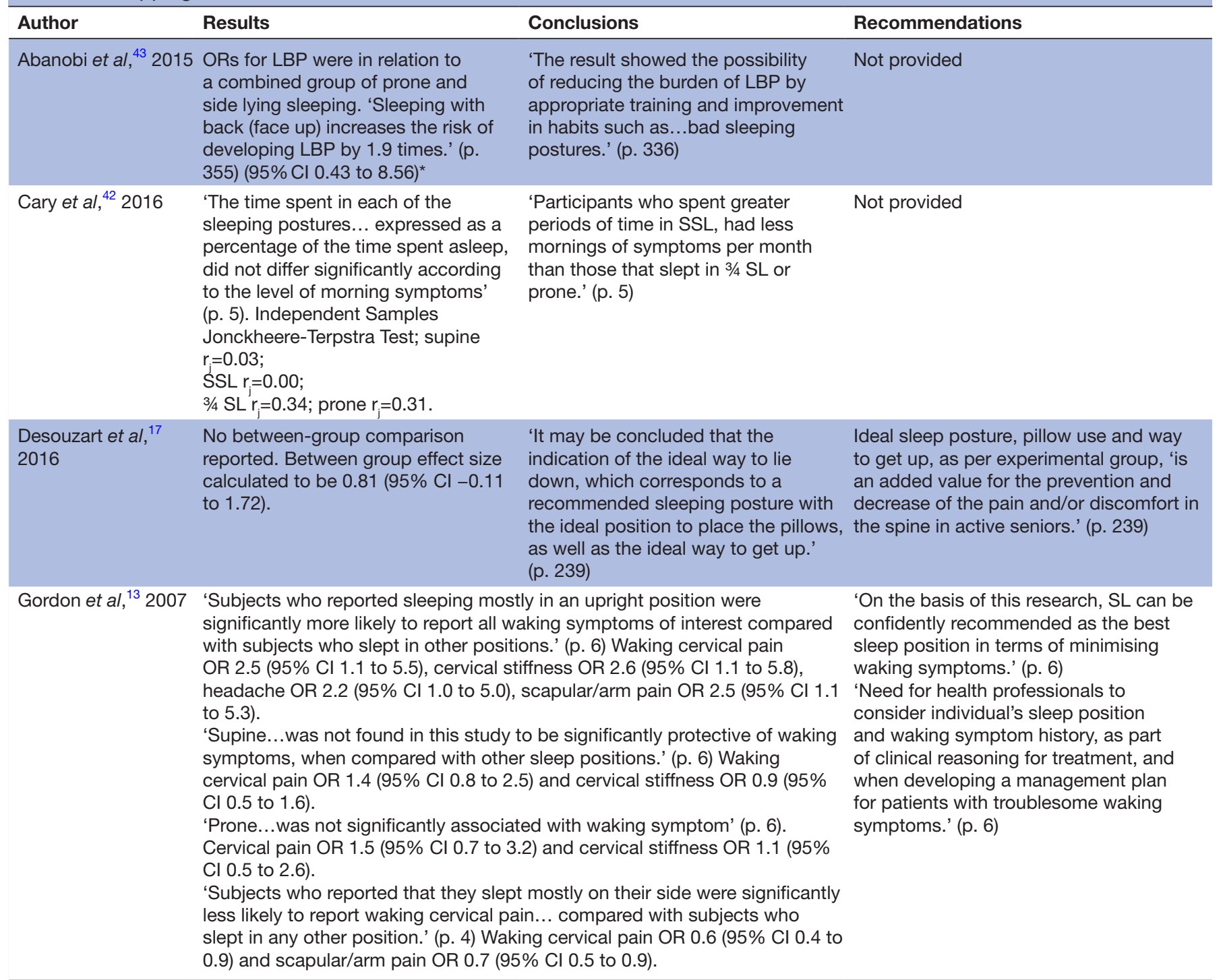

${ }^{*}$ The $\mathrm{Cl}$ was recalculated as it was suspected wrong due a typographical error. The original value was 0.431 .

$3 / 4 \mathrm{SL}=3 / 4$ side lying; $r j=$ effect size $r$ for Jonckheere-Terpstra test .

LBP = low back pain; SSL = supported side lying; VAS = Visual Analogue Scale.

intervention group and were therefore excluded from the three epidemiological studies. ${ }^{13} 4243$ Question 27 was applicable for all but the cross-sectional study. ${ }^{42}$ In the reporting subsection, questions $1-10$, studies were well documented with one different applicable question not completed by each study, enabling readers to draw unbiased assessments of each study's findings. Questions 11-13 (external validity) were poorly reported, with all studies failing to quantify the proportion of participants that were asked, relative to the proportion of participants that were accepted into studies. All studies reported using either random ${ }^{13} 1743$ or consecutive sampling. ${ }^{42}$ Internal validity, questions 14-20, examined measurement bias and apart from question 15 were well documented. In all studies, no attempt was made to blind researchers measuring the outcome variables. However, in one epidemiological study, the interview method precluded the need for blinding of interviewers. ${ }^{13}$ All the remaining questions were well documented, except for question 25 which examined confounding factors. This was poorly documented except for one study, ${ }^{48}$ in which a multivariate analysis was reported in a subsequent study, using the same data. The body of evidence in this scoping review is rated as moderate to strong quality.

Authors identified reliance on self-report to examine sleep posture ${ }^{17}$ and symptoms ${ }^{48}$ as a limitation. Authors identified small sample sizes, as limiting their ability to draw firm conclusions from the obtained results. ${ }^{13} 17$ Authors identified restricted time as a limitation, for the period available for data collection, ${ }^{43}$ and for participants to learn a new sleeping habit. ${ }^{17}$ Limitations as reported by authors are described in online supplementary file 2. 
Table 4 Critical appraisal of included studies using the Downs and Black checklist

\begin{tabular}{|c|c|c|c|c|c|c|}
\hline \multirow{2}{*}{$\begin{array}{l}\text { Section } \\
\text { Reporting }\end{array}$} & \multicolumn{2}{|c|}{ Questions } & \multirow{2}{*}{$\begin{array}{l}\text { Abanobi et } \\
\text { al, }{ }^{43} 2015 \\
Y\end{array}$} & \multirow{2}{*}{$\begin{array}{l}\text { Cary et } \\
\text { al, }^{42} 2016 \\
Y\end{array}$} & \multirow{2}{*}{$\begin{array}{l}\text { Desouzart } \\
\text { et } \\
\text { al, }^{17} 2016 \\
Y\end{array}$} & \multirow{2}{*}{$\begin{array}{l}\text { Gordon et } \\
a_{1,}^{13} 2007 \\
Y\end{array}$} \\
\hline & 1 & $\begin{array}{l}\text { Is the hypothesis/aim/objective of the study clearly } \\
\text { described? }\end{array}$ & & & & \\
\hline & 2 & $\begin{array}{l}\text { Are the main outcomes to be measured clearly described } \\
\text { in the Introduction or Methods section? }\end{array}$ & $\mathrm{N}$ & Y & Y & $\mathrm{Y}$ \\
\hline & 4 & Are the interventions of interest clearly described? & $\mathrm{x}$ & $\mathrm{X}$ & Y & $\mathrm{x}$ \\
\hline & 5 & $\begin{array}{l}\text { Are the distributions of principal confounders in each } \\
\text { group of subjects to be compared clearly described? }\end{array}$ & ${ }^{*} Y$ & $x$ & ${ }^{*} Y$ & ${ }^{*} Y$ \\
\hline & 6 & Are the main findings of the study clearly described? & Y & $\mathrm{Y}$ & $\mathrm{Y}$ & Y \\
\hline & 7 & $\begin{array}{l}\text { Does the study provide estimates of the random } \\
\text { variability in the data for the main outcomes? }\end{array}$ & $\mathrm{Y}$ & Y & $\mathrm{Y}$ & Y \\
\hline & 9 & $\begin{array}{l}\text { Have the characteristics of patients lost to follow-up been } \\
\text { described? }\end{array}$ & $X$ & $x$ & Y & $x$ \\
\hline & 10 & $\begin{array}{l}\text { Have actual probability values been reported (eg, } 0.035 \\
\text { rather than }<0.05) \text { for the main outcomes except where } \\
\text { the probability value is less than } 0.001 \text { ? }\end{array}$ & Y & Y & Y & $\mathrm{N}$ \\
\hline \multirow[t]{2}{*}{$\begin{array}{l}\text { External } \\
\text { validity }\end{array}$} & 11 & $\begin{array}{l}\text { Were the subjects asked to participate in the study } \\
\text { representative of the entire population from which they } \\
\text { were recruited? }\end{array}$ & $\mathrm{Y}$ & Y & $\mathrm{N}$ & $\mathrm{Y}$ \\
\hline & 12 & $\begin{array}{l}\text { Were those subjects who were prepared to participate } \\
\text { representative of the entire population from which they } \\
\text { were recruited? }\end{array}$ & $U$ & $\mathrm{~N}$ & $\mathrm{~N}$ & $\mathrm{~N}$ \\
\hline \multirow{5}{*}{$\begin{array}{l}\text { Internal } \\
\text { validity: bias }\end{array}$} & 16 & $\begin{array}{l}\text { If any of the results of the study were based on 'data } \\
\text { dredging', was this made clear? }\end{array}$ & Y & Y & $\mathrm{Y}$ & Y \\
\hline & 17 & $\begin{array}{l}\text { In trials and cohort studies, do the analyses adjust } \\
\text { for different lengths of follow-up of patients, or in } \\
\text { case-control studies, is the time period between the } \\
\text { intervention and outcome the same for cases and } \\
\text { controls? }\end{array}$ & Y & $x$ & Y & $x$ \\
\hline & 18 & $\begin{array}{l}\text { Were the statistical tests used to assess the main } \\
\text { outcomes appropriate? }\end{array}$ & $\mathrm{Y}$ & Y & $\mathrm{Y}$ & $\mathrm{Y}$ \\
\hline & 19 & Was compliance with the intervention/s reliable? & $\mathrm{X}$ & $\mathrm{X}$ & $U$ & $\mathrm{X}$ \\
\hline & 20 & $\begin{array}{l}\text { Were the main outcome measures used accurate (valid } \\
\text { and reliable)? }\end{array}$ & Y & Y & Y & Y \\
\hline
\end{tabular}

Continued 
Table 4 Continued

\begin{tabular}{|c|c|c|c|c|c|c|}
\hline \multirow{2}{*}{$\begin{array}{l}\text { Section } \\
\text { Internal } \\
\text { validity: } \\
\text { confounding }\end{array}$} & \multicolumn{2}{|c|}{ Questions } & \multirow{2}{*}{$\begin{array}{l}\begin{array}{l}\text { Abanobi et } \\
\text { al, }{ }^{43} 2015\end{array} \\
\mathrm{Y}\end{array}$} & \multirow{2}{*}{$\begin{array}{l}\text { Cary et } \\
a^{42},{ }^{2} 2016 \\
X\end{array}$} & \multirow{2}{*}{$\begin{array}{l}\text { Desouzart } \\
\text { et } \\
\text { al, }^{17} \quad 2016 \\
\mathrm{Y}\end{array}$} & \multirow{2}{*}{$\begin{array}{l}\text { Gordon et } \\
\text { al, }{ }^{13} 2007 \\
Y\end{array}$} \\
\hline & 21 & $\begin{array}{l}\text { Were the patients in different intervention groups (trials } \\
\text { and cohort studies) or were the cases and controls (case- } \\
\text { control studies) recruited from the same population? }\end{array}$ & & & & \\
\hline & 22 & $\begin{array}{l}\text { Were study subjects in different intervention groups (trials } \\
\text { and cohort studies) or were the cases and controls (case- } \\
\text { control studies) recruited over the same period of time? }\end{array}$ & Y & $\mathrm{x}$ & $\mathrm{Y}$ & $\mathrm{x}$ \\
\hline & 23 & Were study subjects randomised to intervention groups? & $\mathrm{X}$ & $\mathrm{X}$ & $\mathrm{Y}$ & $\mathrm{X}$ \\
\hline & 24 & $\begin{array}{l}\text { Was the randomised intervention assignment concealed } \\
\text { from both patients and healthcare staff until recruitment } \\
\text { was complete and irrevocable? }\end{array}$ & $\mathrm{x}$ & $\mathrm{X}$ & $U$ & $\mathrm{x}$ \\
\hline & 25 & $\begin{array}{l}\text { Was there adequate adjustment for confounding in the } \\
\text { analyses from which the main findings were drawn? }\end{array}$ & $\mathrm{N}$ & $\mathrm{N}$ & $\mathrm{N}$ & $\mathrm{Y}$ \\
\hline Score & & & $14 / 17$ & $9 / 12$ & $19 / 28$ & $12 / 14$ \\
\hline Percentage & & & 82 & 75 & 68 & 86 \\
\hline
\end{tabular}

$\mathrm{N}=$ no $=0$ points, $\mathrm{Y}=$ yes $=1$ points, ${ }^{*} \mathrm{Y}=2$ points, $\mathrm{U}=$ unable to determine $=0, \mathrm{X}=$ not applicable (see Quality of Evidence section). Evidence levels $=$ strong $(>75 \%)$, moderate $(50 \%-74 \%)$, limited $(25 \%-49 \%)$ and poor quality $(<24 \%) .{ }^{47}$

\section{DISCUSSION}

To our knowledge, this scoping review is the first to establish the body of evidence regarding the research question; relationships between sleeping posture and spinal symptoms. Generally, there was limited available research. In regard to objective 1; research designs and populations studied for the research question, a variety of study designs and participant populations were used. One study was a controlled pilot trial. With regard to objective 2; types of specific methodology used to address the research question, sleep was assessed in a domestic environment in all studies, with self-report used to measure sleep posture in all studies. Pain was the most common outcome measure of symptoms. In respect to objective 3; results, conclusions and recommendations, authors recommended side lying as the sleep posture least likely to provoke cervical or lumbar spinal symptoms. Studies included in this scoping review were of moderate to strong quality as assessed using the Downs and Black critical appraisal tool. Nonetheless, considerably more research, including longitudinal studies, is required before causal relationships between sleep posture and spinal symptoms could be concluded.

The study designs identified in this scoping review were appropriate to use for the research question. The variety of study designs prevented data pooling and a scoping review remained the most appropriate approach to synthesise the research. The age and gender ratios of included studies were not representative of typical cervical and lumbar pain populations. ${ }^{1-3}$ Generalisation of the results of the included studies needs to be considered with some caution because of a strong gender bias in two studies ${ }^{173}$ and a restricted age of included participants in one study. ${ }^{17}$ In general, small sample sizes were used. The type of study designs and patient populations identified in this scoping review have provided preliminary information regarding relationships between sleep posture and spinal symptoms, but there were not enough high-quality studies to adequately answer our research question.

The most common adult sleep postures are side lying, supine and prone, ${ }^{28} 4950$ which were the postures examined by the studies in this review. Side lying is the sleep posture that greater than $60 \%$ of European adults adopt for the majority of the night. ${ }^{2849}{ }^{50}$ For this reason, one study divided side lying into two sleep postures, based on symmetry and plausible spinal load. These authors identified a trend that participants spending more time in symmetrical side lying reported less morning symptoms than those in asymmetrical side lying. ${ }^{42}$ Although all studies in this review used self-report to report sleep posture, some authors identified this as a limitation ${ }^{13} 1742$ and inaccuracy associated with sleep posture self-report can be as high as $33 \% .{ }^{5152}$ It, therefore, seems prudent to not rely purely on self-report and clinicians would have higher confidence when advising people with pain about sleep posture, if research included both self-report and a valid and reliable measure of sleep posture, such as included in one study. ${ }^{42}$

The anatomical features of the cervical and lumbar spine are different and it is plausible that sleeping postures could affect each area differently. For example, studies in this review indicated sleeping in supine was 
associated with lumbar symptoms, ${ }^{43}$ but not associated with cervical symptoms. ${ }^{13}$ Pain was measured in all studies, which is appropriate given cervical and lumbar pain are leading contributors across all age groups and countries to musculoskeletal disability. ${ }^{1}$ However, characteristics like intensity, frequency or the onset time of pain were not consistently measured and are important to better understand the overall impact pain is having on daily function. ${ }^{53}$ With regard to the relationship between sleep posture and time of onset of spinal symptoms, only half of the studies examined waking symptoms. ${ }^{13} 42$ Waking spinal symptoms are rarely present every morning, which may be due to an individual's variation in sleep posture routine. To better understand the temporal relationships between sleep posture and spinal symptoms, it would be important to record spinal symptoms on first waking.

Spinal pain is a major and growing global health problem with increasing rates of disability. ${ }^{1}$ For the past 20 years, there has been a strong biomedical focus on pathoanatomy as the cause of spinal pain. However, in the case of lumbar pain, only $8 \%-15 \%$ of cases has a specific tissue identified as the cause. ${ }^{54}$ Concurrently, there has been an escalation in imaging, opioid prescription, injections and surgery, with questionable benefit $^{55-57}$ and higher risks. ${ }^{8} 58$ Changing physical risk factors like type of movement pattern, ${ }^{59}$ level of strength and conditioning ${ }^{6061}$ and sustained or repeated postures, ${ }^{62} 63$ are relatively risk free, cost-effective and show great potential. Sleep posture is an example of a sustained physical risk factor that is modifiable. ${ }^{64} 65$ Clinical recommendations by authors included in this review included considering sleep posture when developing management plans for people with waking spinal symptoms ${ }^{13}$ and education to change symptomatic sleep postures. ${ }^{43}$ With regard to recommending a sleep posture to minimise spinal symptoms, this review finds that the side lying posture for the cervical spine, ${ }^{13}$ and side lying and supine were the sleep postures recommended by authors for those with lumbar spinal pain. ${ }^{17}$ However, there is a lack of high-quality studies from which to draw firm recommendations.

Based on the findings of this scoping review, we offer the following recommendations to improve the quality of future research. Research samples should be large enough to achieve statistical goals and sample demographics should be representative of those in the broader population with cervical and lumbar pain. Ideally studies should account for confounding factors such as age and gender through study design or statistical analysis. It would be preferable to differentiate spinal symptoms according to location, rather than considering spinal symptoms as a single group, due to differences in spinal anatomy, function and referral of symptoms. It is also recommended to divide spinal symptoms into categories such as pain, stiffness and bothersomeness, to determine if one or more have greater clinical relevance. Using a valid, objective measure of sleep posture instead of self-report, would also enable determination of time spent in each sleep posture and the number of sleep posture changes. As side lying appears to be associated with less cervical and possibly spinal symptoms generally, it would be worthwhile in future research to confirm this relationship and to further explore whether some subtypes of side lying postures are less provocative of spinal symptoms than others. It would also be informative to consider the temporal aspect of spinal symptoms. That is, recording spinal symptoms on first waking before they are influenced by daytime activities. Sleep posture is potentially modifiable following education ${ }^{17}$ and education is a non-invasive and low-cost intervention which should be further explored in future research using larger scale longitudinal studies.

Acknowledgements Author (DC) acknowledges support from Australian Government Research Training Program Scholarship in supporting this research.

Contributors DC, LM and KB designed the study. DC and LM collected data and conducted data analysis. DC wrote the manuscript. DC and LM undertook interpretation of findings and were involved in drafting the manuscript. All authors were involved in revision of the manuscript gave final approval for submission and publication.

Funding DC received PhD. scholarship funding from Australian Government Research Training Program.

Competing interests None declared.

Patient consent for publication Not required.

Provenance and peer review Not commissioned; externally peer reviewed.

Data sharing statement No additional data are available.

Open access This is an open access article distributed in accordance with the Creative Commons Attribution Non Commercial (CC BY-NC 4.0) license, which permits others to distribute, remix, adapt, build upon this work non-commercially, and license their derivative works on different terms, provided the original work is properly cited, appropriate credit is given, any changes made indicated, and the use is non-commercial. See: http://creativecommons.org/licenses/by-nc/4.0/.

\section{REFERENCES}

1. Hurwitz EL, Randhawa K, Yu H, et al. The global spine care initiative: a summary of the global burden of low back and neck pain studies. Eur Spine J 2018;27:1-6.

2. Côté P, Cassidy JD, Carroll LJ, et al. The annual incidence and course of neck pain in the general population: a population-based cohort study. Pain 2004;112:267-73.

3. Hoy D, Bain C, Williams $\mathrm{G}$, et al. A systematic review of the global prevalence of low back pain. Arthritis \& Rheumatism 2012;64:2028-37.

4. Ekman M, Johnell O, Lidgren L. The economic cost of low back pain in Sweden in 2001. Acta Orthop 2005;76:275-84.

5. Wasiak R, Kim J, Pransky G. Work disability and costs caused by recurrence of low back pain: longer and more costly than in first episodes. Spine 2006;31:219-25.

6. Croft PR, Lewis M, Papageorgiou AC, et al. Risk factors for neck pain: a longitudinal study in the general population. Pain 2001;93:317-25.

7. Hestbaek L, Leboeuf-Yde C, Kyvik KO, et al. The course of low back pain from adolescence to adulthood: eight-year follow-up of 9600 twins. Spine 2006;31:468-72.

8. Manchikanti L, Singh V, Datta S, et al. Comprehensive review of epidemiology, scope, and impact of spinal pain. Pain Physician 2009;12:35-70.

9. Hodges $\mathrm{P}$, van den Hoorn W, Dawson A, et al. Changes in the mechanical properties of the trunk in low back pain may be associated with recurrence. J Biomech 2009;42:61-6.

10. Cho Y, Song Y, Cha Y, et al. Acupuncture for chronic low back pain. Spine 2013;38:549-57.

11. Croft PR, Dunn KM, Raspe H. Course and prognosis of back pain in primary care: the epidemiological perspective. Pain 2006;122:1-3. 
12. Desouzart G, Vilar E, Melo F, Matos R, et al. eds. Human bed interaction: a methodology and tool to measure postural behavior during sleep of the air force military. Heraklion, Greece: 3rd International Conference on Design, User Experience, and Usability, 2014.

13. Gordon S, Grimmer K, Trott P. Sleep position, age, gender, sleep quality and waking cervico-thoracic symptoms. Internet Journal of Allied Health Sciences and Practice 2007;5.

14. Corrigan B, March L. Cervical spine dysfunction: a pain in the neck. Patient Management 1984;8:48-53.

15. Gordon SJ, Trott P, Grimmer KA. Waking cervical pain and stiffness, headache, scapular or arm pain: gender and age effects. Aust $J$ Physiother 2002;48:9-15.

16. McKenzie R. The cervical and thoracic spine: mechanical diagnosis and therapy. Waikanae: Spinal Publications, 1990.

17. Desouzart G, Matos R, Melo F, et al. Effects of sleeping position on back pain in physically active seniors: A controlled pilot study. Work 2015;53:235-40.

18. Gracovetsky SA. The resting spine. A conceptual approach to the avoidance of spinal reinjury during rest. Phys Ther 1987;67:549-53.

19. Dolan P, Earley M, Adams MA. Bending and compressive stresses acting on the lumbar spine during lifting activities. $J$ Biomech 1994;27:1237-48.

20. Kingma I, Baten CT, Dolan P, et al. Lumbar loading during lifting: a comparative study of three measurement techniques. J Electromyogr Kinesiol 2001;11:337-45.

21. Oxland TR. Fundamental biomechanics of the spine--What we have learned in the past 25 years and future directions. $J$ Biomech 2016:49:817-32.

22. Adams MA, Hutton WC. The relevance of torsion to the mechanical derangement of the lumbar spine. Spine 1981;6:241-8.

23. Solomonow M. Neuromuscular manifestations of viscoelastic tissue degradation following high and low risk repetitive lumbar flexion. $J$ Electromyogr Kinesiol 2012;22:155-75.

24. Hill S, Goldsmith J. Biomechanics and prevention of body shape distortion. Tizard Learning Disability Review 2010;15:15-32.

25. Waugh A, Hill S. Body shape distortion: promoting postural care at night. Learning Disability Practice 2009;12:25-9.

26. Murayama R, Kubota T, Kogure T, et al. The effects of instruction regarding sleep posture on the postural changes and sleep quality among middle-aged and elderly men: a preliminary study. Biosci Trends 2011:5:111-9.

27. Buchbinder R, van Tulder M, Öberg B, et al. Low back pain: a call for action. Lancet 2018;391:2384-8.

28. De Koninck J, Lorrain D, Gagnon P. Sleep positions and position shifts in five age groups: an ontogenetic picture. Sleep 1992;15:143-9.

29. Goldman SM. Nocturnal neuropathic pain in diabetic patients may be caused by spinal stenosis. Diabet Med 2005;22:1763-5.

30. Desouzart G, Filgueiras E, Melo F, Matos R, et al. eds. Human body-sleep system interaction in residence for university students: Evaluation of interaction patterns using a system to capture video and software with observation of postural behaviors during sleep. Kraków, Poland: 5th International Conference on Applied Human Factors and Ergonomics, 2014.

31. Arksey H, O'Malley L. Scoping studies: towards a methodological framework. Int J Soc Res Methodol 2005;8:19-32.

32. Khalil H, Peters M, Godfrey CM, et al. An evidence-based approach to scoping reviews. Worldviews Evid Based Nurs 2016;13:118-23.

33. Levac D, Colquhoun H, O'Brien KK. Scoping studies: advancing the methodology. Implement Sci 2010;5:9.

34. Peters MD, Godfrey CM, Khalil H, et al. Guidance for conducting systematic scoping reviews. Int J Evid Based Healthc 2015;13:141-6.

35. Tricco AC, Lillie E, Zarin W, et al. PRISMA extension for scoping reviews (PRISMA-ScR): checklist and explanation. Ann Intern Med 2018;169.

36. Covidence. Melbourne Australia: veritas health innovation, 2018.

37. Michaleff ZA, Costa LO, Moseley AM, et al. CENTRAL, PEDro, PubMed, and EMBASE are the most comprehensive databases indexing randomized controlled trials of physical therapy interventions. Phys Ther 2011;91:190-7.

38. EndNote. X8 ed. Philadelphia USA: Clarivate Analytics, 2018

39. Downs SH, Black N. The feasibility of creating a checklist for the assessment of the methodological quality both of randomised and non-randomised studies of health care interventions. J Epidemiol Community Health 1998;52:377-84.
40. Olivo SA, Macedo LG, Gadotti IC, et al. Scales to assess the quality of randomized controlled trials: a systematic review. Phys Ther 2008;88:156-75.

41. Korakakis V, Whiteley R, Tzavara A, et al. The effectiveness of extracorporeal shockwave therapy in common lower limb conditions: a systematic review including quantification of patient-rated pain reduction. Br J Sports Med 2018:52:387-407.

42. Cary D, Collinson R, Sterling M, et al. Examining the relationship between sleep posture and morning spinal symptoms in the habitual environment using infrared cameras. Journal of Sleep Disorders: Treatment and Care 2016.

43. Abanobi O, Ayeni G, Ezeugwu C, et al. Risk-disposing habits of lowback pain amongst welders and panel beaters in Owerri, southeast Nigeria. Indian Journal of Public Health 2015:6:332-7.

44. Centre for Evaluation and Monitoring. Effect size calculator. 2018 https://www.cem.org/effect-size-calculator

45. IBM Corporation. SPSS statistics for Mac. 25.0 ed. New York:USA: Armonk, 2018

46. Field A. Discovering statistics using IBM SPSS Statistics. 5 ed. Los Angeles: SAGE Publications, 2017.

47. Hignett $S$. Intervention strategies to reduce musculoskeletal injuries associated with handling patients: a systematic review. Occup Environ Med 2003;60:e6-e.

48. Gordon S, Grimmer K, Trott P. Understanding sleep quality and waking cervico-thoracic symptoms. Internet Journal of Allied Health Sciences and Practice 2007;5:1-12.

49. Haex B. Back and bed: ergonomic aspects of sleeping. Boca Raton: CRC Press, 2005.

50. Gordon S, Grimmer K, Trott P. Self reported versus recorded sleep position: an observational study. The Internet Journal of Allied Health Science and Practice 2004;2:1-10.

51. Yu C. Why is self-report of sleep position sometimes unreliable? Sleep and Hypnosis 2018:20:105-13.

52. Kaplowitz K, Blizzard S, Blizzard DJ, et al. Time spent in lateral sleep position and asymmetry in glaucoma. Invest Ophthalmol Vis Sci 2015;56:3869-74.

53. Gordon S, Grimmer-Somers K. Your pillow may not guarantee a good night's sleep or symptom-free waking. Physiotherapy Canada 2010;63:183-90.

54. Waddell G. The back pain revolution. 2 ed. Edinburgh: Churchill Livingstone, 2004

55. Atlas SJ, Keller RB, Wu YA, et al. Long-term outcomes of surgical and nonsurgical management of sciatica secondary to a lumbar disc herniation: 10 year results from the maine lumbar spine study. Spine 2005;30:927-35.

56. Friedly J, Chan L, Deyo R. Increases in lumbosacral injections in the Medicare population: 1994 to 2001. Spine 2007;32:1754-60.

57. Runciman WB, Hunt TD, Hannaford NA, et al. CareTrack: assessing the appropriateness of health care delivery in Australia. Med J Aust 2012;197:100-5

58. Luo X, Pietrobon R, Hey L. Patterns and trends in opioid use among individuals with back pain in the United States. Spine 2004:29:884-90.

59. O'Sullivan P. Diagnosis and classification of chronic low back pain disorders: maladaptive movement and motor control impairments as underlying mechanism. Man Ther 2005;10:242-55.

60. Gabel CP, Mokhtarinia HR, Hoffman J, et al. Does the performance of five back-associated exercises relate to the presence of low back pain? A cross-sectional observational investigation in regional Australian council workers. BMJ Open 2018;8:e020946.

61. Micheo W, Baerga L, Miranda G. Basic principles regarding strength, flexibility, and stability exercises. PM\&R 2012;4:805-11.

62. Solomonow M, Baratta RV, Banks A, et al. Flexion-relaxation response to static lumbar flexion in males and females. Clin Biomech 2003;18:273-9.

63. Solomonow M, Zhou BH, Lu Y, et al. Acute repetitive lumbar syndrome: a multi-component insight into the disorder. J Bodyw Mov Ther 2012;16:134-47.

64. Cartwright R, Ristanovic R, Diaz F, et al. A comparative study of treatments for positional sleep apnea. Sleep 1991;14:546-52.

65. van Maanen JP, de Vries N. Long-term effectiveness and compliance of positional therapy with the sleep position trainer in the treatment of positional obstructive sleep apnea syndrome. Sleep 2014;37:1209-15. 